\title{
El justo lugar de Octavio Paz*
}

* Molina Carrillo, Germán; Cansino, César; Gallardo, Omar, Octavio Paz sin concesiones. Quince miradas críticas, México, BUAP-Grupo Editorial Mariel, 2016, 263 pp.

Tla-Melaua, revista de Ciencias Sociales. Facultad de Derecho y Ciencias Sociales. Benemérita Universidad Autónoma de Puebla, México / issn: 1870-6916 / Nueva Época, Año 10, No 40, abril/septiembre 2016, pp. 216-220. 
Durante el siglo xx, los países de la periferia cultural dieron a luz a gigantes monstruosos. Un puñado de escritores causó que la mirada del centro se alargara a los confines; al Sur. En una orilla del continente, Jorge Luis Borges urdía laberintos, perversiones textuales y relatos con maquinarias cronométricas y perfectas; en la otra, Octavio Paz, casi de manera milagrosa, tejía una poesía impecable, cautivadora y nueva.

Me siento obligado a vincular a ambos escritores, un poco por el tiempo que compartieron (aunque Borges fuera más contemporáneo de Alfonso Reyes), otro poco por los géneros que cultivaron (el ensayo y la poesía), pero sobre todo por el poder que adquirieron en los últimos años de sus vidas. Paz fue un gran intelectual, ni se niega ni se duda, pero también fue, como Borges, un temido dictador cultural que definió el curso de la literatura nacional.

Estas figuras tienden a petrificarse durante años. La fama y la perfección técnica las vuelve intocables. El tiempo, sin embargo, proscribe la idolatría y exige a los nuevos intelectuales deshacerse de objetos de culto ciego. Por eso son tan importantes las publicaciones críticas, como Octavio Paz sin concesiones. Quince miradas criticas. Desde el prefacio, los compiladores, Cansino, Molina y Gallardo, apuntan a la necesidad de someter a crítica la obra de Paz, en vez de embalsamarla y tenerla por objeto reluciente e intocable de culto.

La apertura de la obra está presidida por el comentario de Agapito Maestre, filósofo y politólogo español. Aquí se afirma que en la cultura del siglo xx y la contemporánea hubo (y hay) pocos pensadores que fungieran como modelos de universalidad. Para Maestre, uno de ellos es Paz; para mí, el otro es Borges. También se anotan algunos de los leitmotiv de esta obra: la crítica de Paz a la modernidad y sus inmensas deudas de gratitud con Alfonso Reyes y José Ortega y Gasset.

Esta obra se encuentra dividida en apartados que estudian a fondo todas las dimensiones de Paz. Ante esto, Anthony Stanton nos recuerda que Paz era fundamentalmente un poeta (Paz mismo lo afirmó varias veces), y que, por tanto, hablar de su dimensión poética es una redundancia; me atrevería añadir: como hablar de la dimensión húmeda del agua. Sin embargo, esta franca disección de la obra orgánica paceana debe entenderse como herramienta de análisis, en todo su sentido.

\footnotetext{
* Licenciado en literatura. Editor especializado en libros académicos de ciencias sociales y humanidades. (luisgerobles@gmail.com)
} 
Por otro lado, en Octavio Paz sin concesiones no se advierte una mutilación. En todas estas dimensiones se cuelan rasgos de las otras. Por lo tanto, esta división no hace más que acentuar que el rostro de Paz era el de un poeta, imbuido en el cultivo del ensayo e interesado por la política y la vida intelectual, tanto mexicana como universal; pero un poeta.

En la primera parte, "Octavio Paz entre nosotros", Gabriel Zaid, Enrico Mario Santí y Braulio Hornedo pincelan el rostro del carácter y de la trayectoria de Paz. Delinean además su faceta política, los grandes rasgos de su obra poética y las influencias, como lo afirmara Maestre en el prólogo, de Reyes y Ortega y Gasset. Esta sección del libro conserva el talante oral del coloquio que lo originó. El sabor conversacional se filtra por la lectura.

Me parece una excelente decisión situar en primer lugar, inmediatamente después de la semblanza biográfica, la faceta dedicada a la obra poética de Paz. En esta segunda parte, encontramos las puntuales y minuciosas aportaciones de Stanton, Luis Roberto Vera, y Sebastián Pineda Buitrago. Acaso, en esta sección no estamos ante una lectura introductoria; los capítulos (destaco el de Stanton) requieren cuando menos una lectura de la poesía de Paz, sobre todo de uno de sus mejores poemarios: La estación violenta, que se analiza a fondo.

De este mismo capítulo sobre La estación violenta, me parece entrañable el señalamiento de Stanton concerniente a la facilidad (vale decir también el peligro) de sacar a Paz de su contexto para fines ideológicos. Es por estas descontextualizaciones que le parece un acto de equilibrismo sin red que se hubiera dividido esta obra en las facetas paceanas. Sin embargo, estos temores se disipan en el discurso de la obra, que en ningún momento hace de Paz un estandarte, sino un riguroso objeto de análisis.

Este apartado también da cuenta de los encuentros de Paz con otras artes, como la pintura. Para tal efecto, Vera señala los puntos de contacto (además de la evidente génesis) entre la obra del pintor surrealista Roberto Matta con el poema "La casa de la mirada". Cabe mencionar también la atención de desentrañar las huellas del impacto de la cultura mesoamericana en la obra paceana. Por otro lado, Pineda Buitrago resalta el nodo entre la poesía y el pensamiento político de Paz: el amor y el erotismo.

En la siguiente sección, Liliana Weinberg, Israel Arroyo y Francisco Gil Villegas se encargan de trazar el cauce de la obra ensayística de Paz. Desde el uso hasta la misma poética del lenguaje, pasando por la analogía y el elemento poético en su prosa ensayística, por la importancia de Paz en el desarrollo del ensayo latinoamericano, hasta llegar a los escarceos de Paz con los temas políticos, este apartado representa una panorámica, por un lado, de los autores que influenciaron a Paz y, por otro, de los que encontraron en él la génesis de ideas influyentes, como el caso de Jürgen Habermas. (En este punto es imposible no notar el punto de contacto con Borges, cuyo 
ensayo "el idioma analítico de John Wilkins" fue una declarada influencia del libro Las palabras y las cosas, de Michel Foucault). La declaración forzada en este rubro es, como delinea Gil Villegas, que Paz fue conocido a nivel mundial gracias a sus ensayos.

A partir de este punto, la tarea crítica se vuelve menos problemática. Habría que postular la casi insalvable dificultad que presenta hacer un juicio severo a su poesía, que quizá no sea tan violenta tratándose de sus ensayos. De $E l$ laberinto de la soledad se ha escrito en varias ocasiones que es el libro de Paz que más ha envejecido; no obstante, hay quienes sostienen, como Bellinghausen, que este evidente (y no menos inevitable) envejecimiento no le quita valor. Sin embargo, emitir un juicio crítico al Paz intelectual o al Paz pensador autodidacta político presenta menores, aunque no débiles, resistencias.

En la cuarta parte, Yvon Grenier pone sobre la mesa que el mundo de Paz ya no es el nuestro. Por tanto, algunas de sus ideas han quedado rezagadas; por otro lado, describe menos a un pensador político casado con una ideología política que a un amante de la libertad que desconfía de cualquier sistema político (la democracia incluida).

Carlos Ramírez detalla el panorama político-intelectual mexicano y la relación de Paz con el poder estatal. El centro de su análisis es la concepción del poeta mexicano de que los intelectuales debían tener participación política y una postura crítica, pero siempre con independencia de las figuras políticas. Además, pone de relieve el nutrido debate entre Paz y Carlos Monsiváis, la crítica a la televisión abierta. Por último, trata algunos puntos sobre la relación entre Carlos Salinas de Gortari y el nobel mexicano.

Para cerrar el apartado, Xavier Rodríguez Ledesma subraya el comportamiento en Paz en el escenario donde todos están expuestos a equivocarse: el debate actual. Rodríguez apunta al trato desigual que recibió Paz ante sus errores; trata su prisa por forjar una opinión sobre la aparición del EZLN y la respuesta, pronta y severa, de la comunidad intelectual.

En la última parte, "Mito, historia y política en Octavio Paz", Jesús Silva-Herzog Márquez recurre a una vía de análisis que parte de la poesía hacia la política. Afirma tajantemente que Paz, que siempre se afirmó a sí mismo como poeta, pensaba temas como la política y el dinero siempre desde la óptica de la poesía. En el segundo apartado, Omar Gallardo hace un pertinente análisis sobre la idea de Paz sobre la Revolución mexicana. Analiza el vocablo revolución y su carga semántica desde la perspectiva de Paz, quien definía el conflicto bélico de 1910 como una revuelta. Por último, César Cansino enfila su pluma hacia las ideas de identidad nacional esbozadas en El laberinto de la soledad para rescatar aquellas que aún son vigentes y para actualizar las que han caducado. Justifica su análisis por los cambios políticos nacionales que surgieron a raíz del reemplazo de la "dictadura perfecta" a la incipiente democracia actual. 
Como epílogo, Armando González Torres describe el panorama cultural, ahora en vías de extinción del México en que Paz vivió. Este país, alejado en los años y en las ideas políticas donde la figura del poeta e intelectual tenía un papel social, ha dejado de parecerse al de Paz. Como lo afirma González Torres, una figura como la de Paz ya no podría sostenerse: sería demasiado superficial para la academia sociológica y demasiado profunda para los medios masivos. Cerrar el libro tras dicho epílogo deja en el aire una palpitación de nostalgia.

Este libro seguro se constituirá en una obra de referencia en no mucho tiempo. La calidad del trabajo editorial, por lo demás, es muy evidente. Pero lo principal es la calidad de escritores incluidos en esta obra. Sin duda constituye una referencia en la cual descansar y asimilar información tras una lectura atenta de la obra de Paz. Además, es necesario repetir su modus operandi con otros escritores del siglo xx, no tanto como un método de depuración, sino más bien como un proceso de exorcismo.

En el horizonte de los años, los gigantes, como Paz o Borges, aún nos influencian, aún miran hacia abajo desde su altar, aún dictan leyes y proscriben iniciativas. No pierden su hechizo de fascinación; pero han comenzado a parecerse a los moái de la Isla de Pascua: cada vez más recónditos; cada vez más citados, más descontextualizados; cada vez menos entendidos, menos leídos. Este libro no es una libación más al altar de los ídolos, sino una limpieza al templo de la cultura, donde Paz toma no el lugar del dictador eterno, sino su sitio justo en la historia de la cultura y, principalmente, del arte. 